\title{
Targeted deletion of Ruvbl1 results in severe defects of epidermal development and perinatal mortality
}

\author{
Claudia Dafinger ${ }^{1,2,3}$, Thomas Benzing ${ }^{2,3,4,5}$, Jörg Dötsch', Bernhard Schermer ${ }^{2,3,4,5}$ and Max C. Liebau ${ }^{1,2,5^{*}}$ (D)
}

\begin{abstract}
Epidermal development is a complex process of regulated cellular proliferation, differentiation, and tightly controlled cell death involving multiple cellular signaling networks. Here, we report a first description linking the AAA+ (ATPases associated with various cellular activities) superfamily protein Ruvbl1 to mammalian epidermal development. Keratinocyte-specific Ruvb/1 knockout mice (Ruvb/1/f/ K14:Cre $e^{\text {tg }}$ ) show a severe phenotype including dramatic structural epidermal defects resulting in the loss of the functional skin barrier and perinatal death. Thus, Ruvbl1 is a newly identified essential player for the development of differentiated epidermis in mice.
\end{abstract}

\section{Introduction}

The development of the mammalian epidermis is a highly complex multistage process that involves a sequence of steps from epidermal specification to expansion and development of derivative appendages, e.g., hair follicles $[1,2]$. For the precise regulation of epidermal development, several signaling pathways are involved closely regulating the spatiotemporal coordination of cellular proliferation, differentiation, and tightly controlled cell death [1, 3, 4]. Epidermal development has become a model to study developmental mesenchymalepithelial interactions between epidermis and dermis, the specific mechanisms of embryonic wound healing without scarring and cellular mechanisms in rapidly proliferating and self-renewing tissues [1-4].

The two AAA+ (ATPases associated with various cellular activities) superfamily proteins Ruvbl1 (Pontin, Tip48) and Ruvbl2 (Reptin, Tip49) have their central roles in promoting cell proliferation and cell survival. They contribute to various cellular processes including chromatin remodeling

\footnotetext{
* Correspondence: max.liebau@uk-koeln.de

1 Department of Pediatrics, Faculty of Medicine and University Hospital

Cologne, University of Cologne, Kerpener Str. 62, 50937 Cologne, Germany

2Department II of Internal Medicine, Faculty of Medicine and University

Hospital Cologne, University of Cologne, Cologne, Germany

Full list of author information is available at the end of the article
}

(Tip60, Ino80, and Scrap) as well as DNA damage signaling and repair [5-13]. Ruvbl1 is, e.g., required for the assembly and function of multiple protein complexes including the Tip60 complex regulating the tumor suppressor protein p53 $[8,13,14]$. In addition, the Ruvbl proteins or protein complexes involving the Ruvbl proteins modulate transcriptional activity of, e.g., pro-proliferative factors like MYC and $B$-catenin and play important roles in multiple steps of cell cycle progression and cellular metabolism [6, 8, 13]. We recently identified Ruvbl1 as a component of ciliary protein complexes in renal tubular, bronchial, and ependymal epithelial cells [15]. Ruvbl1 also seems to be essential for early embryogenesis in mice $[15,16]$, and it has been suggested that loss of murine stem cell populations may be due to apoptosis [16]. To study the significance of Ruvbl1 in rapidly proliferating and differentiating mammalian tissue in vivo, we generated a targeted knockout of Ruvbl1 in murine epidermal cells. Here, we show that the embryonic loss of Ruvbl1 in mouse epidermis leads to severe developmental defects, resulting in loss of skin architecture and skin barrier defects associated with perinatal death.

(c) The Author(s). 2021 Open Access This article is licensed under a Creative Commons Attribution 4.0 International License, which permits use, sharing, adaptation, distribution and reproduction in any medium or format, as long as you give appropriate credit to the original author(s) and the source, provide a link to the Creative Commons licence, and indicate if changes were made. The images or other third party material in this article are included in the article's Creative Commons licence, unless indicated otherwise in a credit line to the material. If material is not included in the article's Creative Commons licence and your intended use is not permitted by statutory regulation or exceeds the permitted use, you will need to obtain permission directly from the copyright holder. To view a copy of this licence, visit http://creativecommons.org/licenses/by/4.0/. 


\section{Material and methods \\ Mice}

The generation of the $R u v b l 1^{\mathrm{fl}}$ mice was recently described [15]. K14:Cre (MGI: 2177413) expressing the Cre recombinase under the Keratin14 promotor in the epidermis has previously been described [17]. To generate epidermal-specific Ruvbl1-deficient mice, Ruvbl1 $1^{\mathrm{fl}}$ animals and K14:Cre animals were crossed on a $\mathrm{C} 57 \mathrm{Bl} / 6 \mathrm{~N}$ background. The mice were housed according to standardized specific pathogen-free conditions in the animal facility of the University of Cologne. All matings and experiments were conducted in accordance with European, national and institutional guidelines, as approved by the State Office of North Rhine-Westphalia, Department of Nature, Environment and Consumer Protection (8.8750.10.31.08.049 and 84-02.04.2013.A152).

For the preparation of the embryonic mice, the pregnant females were sacrificed by cervical dislocation. Tissue was processed by fixation in $4 \%$ formaldehyde and embedding in paraffin.

\section{Skin barrier assay}

For examination of the skin barrier, intact E18.5 embryos were first dehydrated in increasing amounts of methanol $(25 \%, 50 \%, 75 \%, 100 \%)$. After rehydration in decreasing methanol solutions $(75 \%, 50 \%, 25 \%, 0 \%)$, the embryos were stained in $0.0125 \%$ toluidine blue for 1 min and finally washed in PBS.

\section{Histology}

For histological analysis, embryonic tissue was cut in 3$\mu \mathrm{m}$-thick sections and stained with hematoxylin and eosin using standard techniques. Paraffin was removed from the embedded tissue by xylene treatment and rehydration in graded ethanol. Sections were then stained, firstly, with Mayer's hemalum (Sigma-Aldrich) to visualize nuclei in blue, and secondly, with eosin (Carl Roth) to visualize cytoplasmic structures in red.

\section{Immunostainings}

Embryonic tissue was sliced in 2- $\mu$ m-thick sections and deparaffinated as described above. Antigen retrieval was achieved using heat-induced epitope retrieval and citrate buffer. For immunohistochemical staining, endogenous peroxidases and unspecific antibody binding sites were blocked by treatment with $3 \% \mathrm{H}_{2} \mathrm{O}_{2}$ and the $\mathrm{ABC}$ Kit according to the manufacturer's manual (VectorLabs). Primary antibodies were incubated overnight at $4^{\circ} \mathrm{C}$ in $1 \%$ BSA as indicated. After incubation with the biotin-coupled secondary antibody, antibody signals were visualized by developing the tissue in DAB solution (VectorLabs). Nuclear counterstaining was performed using Mayer's hemalum reagent. For fluorescent staining, tissue was blocked in 5\% normal donkey serum (Jackson ImmunoResearch) and 1\% bovine serum albumin for $1 \mathrm{~h}$ at RT. Primary antibodies were incubated overnight at $4{ }^{\circ} \mathrm{C}$ as indicated. Tissue sections were incubated with fluorophore-coupled secondary antibodies and mounted in Prolong Diamond antifade containing DAPI (Invitrogen).

\section{Antibodies}

The following antibodies were used: Ki67 (Abcam, 1: 500), K14 (Abcam, 1:500), Ruvbl1 (ProteinTech, 1:500), p53 (Leica Biosystems, 1:500), CC3 (Cell Signalling, 1: 200), yH2Ax (Cell Signalling, 1:500), ß-cat (Cell Signalling, 1:500), cMyc (Cell Signalling, 1:500).

\section{Results}

Epidermal Ruvbl1 knockout results in perinatal mortality

To study the role of Ruvbl1 in the epidermis, we crossed the floxed Ruvbl1 mouse line to the K14:Cre mouse line, resulting in a tissue-specific knockout of Ruvbl1 in keratinocytes of the skin epidermis (Fig. 1a). Interestingly, we did not observe living Ruvbl1 ${ }^{\mathrm{fl} / \mathrm{fl}} \mathrm{K} 14: \mathrm{Cr} e^{\mathrm{tg}}$ animals in our postnatal genotypings, although all other genotypes, including $\mathrm{Ruvbll}^{\mathrm{f} / \mathrm{wt}} \mathrm{K} 14: \mathrm{Cr} \mathrm{C}^{\mathrm{tg}}$ animals, developed normally and did not show obvious phenotypes during the follow-up of up to 2 years. Ruvbl1 knockout animals developed in normal Mendelian ratios even until late embryonic stages (Fig. 1b) suggesting that epidermal Ruvbl1 knockout results in perinatal mortality. Effective loss of the Ruvbl1 protein in the epidermis of Ruvbl1 knockout animals was confirmed by immunohistochemistry stainings at day E14.5 (Fig. 1c). Ruvbll ${ }^{\mathrm{f} / \mathrm{wt}} \mathrm{K} 14: \mathrm{Cre}^{\mathrm{tg}}$ animals showed remaining epidermal expression of Ruvbl1 (Suppl. Fig. 1). Macroscopically, the Ruvbl1 ${ }^{\mathrm{fl} / \mathrm{fl}} K 14$ : $\mathrm{Cre}^{\mathrm{tg}}$ embryos at ages E12.5 and E14.5 did not show any obvious difference compared to the control littermates. From day E16.5 on, however, the skin of the Ruvbl $^{\mathrm{t} / \mathrm{l} / \mathrm{I}} \mathrm{K} 14: C r e^{\mathrm{tg}}$ embryos seemed to be thinner and more stretched compared to controls. This was particularly striking when looking at the skin folds on the belly or the eyes of the embryos (Fig. 1d).

\section{Embryonic epidermal loss of Ruvbl1 results in severe defects of epidermal development and function}

To test functional epidermal properties of epidermal Ruvbl1 knockout mice, we performed a skin barrier assay. In this assay, the uptake of toluidine blue indicates defects of the outside-in skin barrier. $\mathrm{Ruvbl1}^{\mathrm{fl} / \mathrm{fl}} \mathrm{K} 14: \mathrm{Cr} e^{\mathrm{tg}}$ clearly showed massive skin barrier defects at E18.5 (Fig. 1e). Histological analysis of $\mathrm{Ruvbl1}^{\mathrm{fl} / \mathrm{fl}} \mathrm{K14}$ :Cre $\mathrm{Ctg}^{\mathrm{tg}}$ mice revealed defects in skin architecture and development already in very early stages (E12.5 and E14.5, Fig. 1f) with dramatic changes at later stages (E16.5 and E18.5). Skin appendages like hair follicles, which develop later, are lacking completely in Ruvbl1 knockout mice. The stainings confirmed the stretched macroscopic 


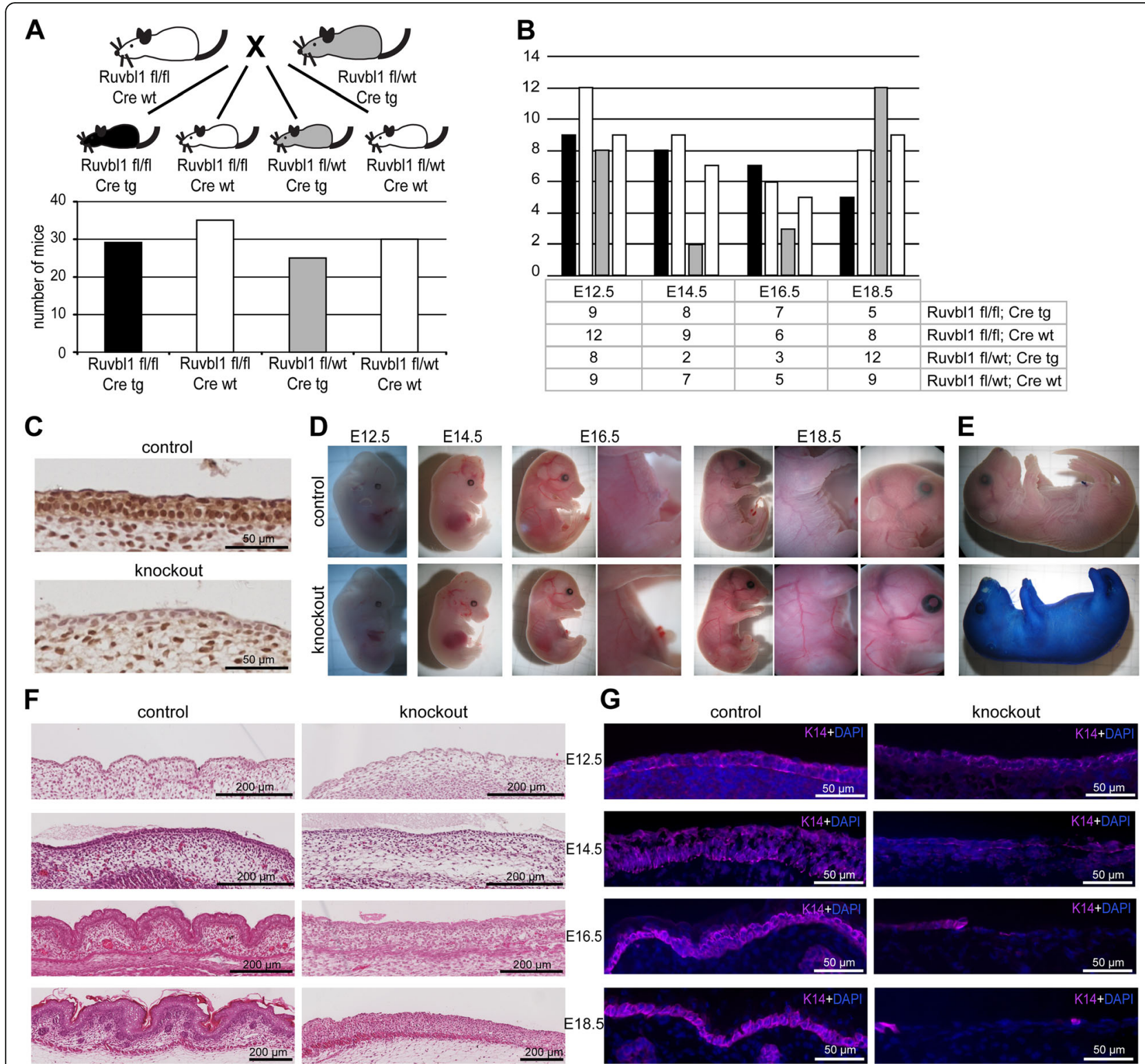

Fig. 1 Epidermal knockout of Ruvbl1 leads to severe skin development defects. a Although no living animals were observed, Ruvb/1 epidermal knockout embryos (Ruvb/ $1^{\mathrm{fl} / \mathrm{fl}} \mathrm{K} 14: \mathrm{Cr} \mathrm{e}^{\mathrm{tg}}$ ) are found in normal Mendelian ratios. The quantification summarizes mice from all embryonic stages examined. b Specific numbers of genotyped animals from different embryonic stages examined do not show a clear-cut pattern (E12.5, E14.5, E16.5, E18.5). c Immunostainings for Ruvbl1 on day E14.5 confirms loss of Ruvbl1 protein in Ruvb/1 knockout mice. Control mice were Ruvbl/ $1^{\mathrm{fl} / \mathrm{K}} \mathrm{K} 14: \mathrm{Cr} \mathrm{e}^{\text {neg }}$. d Macroscopic images of Ruvbl $1^{\mathrm{fl} / \mathrm{fl}} \mathrm{K} 14: \mathrm{Cr} \mathrm{e}^{\mathrm{tg}}$ mice and control littermates demonstrate very thin skin and lacking skin folds in

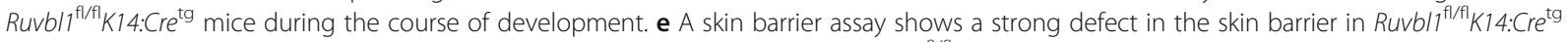
mice. $\mathbf{f}$ Histological HE staining show defects in general skin development in Ruvbl $1^{\text {fl/fl }} \mathrm{K} 14$ :Cre $\mathrm{C}^{\mathrm{tg}}$ mice starting in early embryonic development. $\mathbf{g}$ Immunostaining against K14 shows almost complete loss of epidermal tissue during late embryonic phases in Ruvb/7 ${ }^{\mathrm{fl} / \mathrm{fl}} \mathrm{K} 14: \mathrm{Cr} \mathrm{e}^{\mathrm{tg}} \mathrm{mice}$

appearance of the skin of the embryos. Immunofluorescence stainings of the skin using keratin-14 (K14) as marker for the epidermis showed a nearly complete loss of the K14-positive epidermal skin layer in Ruvbl1 knockout embryos (Fig. 1f).

Given the very early dramatic phenotype, we refrained from in-depth functional studies of signaling cascades in the epidermis in $R u v b l 1^{\mathrm{f} / \mathrm{fl}} K 14: C r e^{\mathrm{tg}}$ mice. In first hypothesis-generating experiments, we evaluated markers of proliferation at an early stage of development. Indeed, $R u v b l 1^{\mathrm{f} / \mathrm{fl}} K 14: \mathrm{Cre} \mathrm{e}^{\mathrm{tg}}$ embryos on day E14.5 showed a reduced signal of Ki67-positive cells in the epidermis (Fig. 2). This was accompanied by a more pronounced signal of p53 staining suggesting an accumulation of the pro-apoptotic 


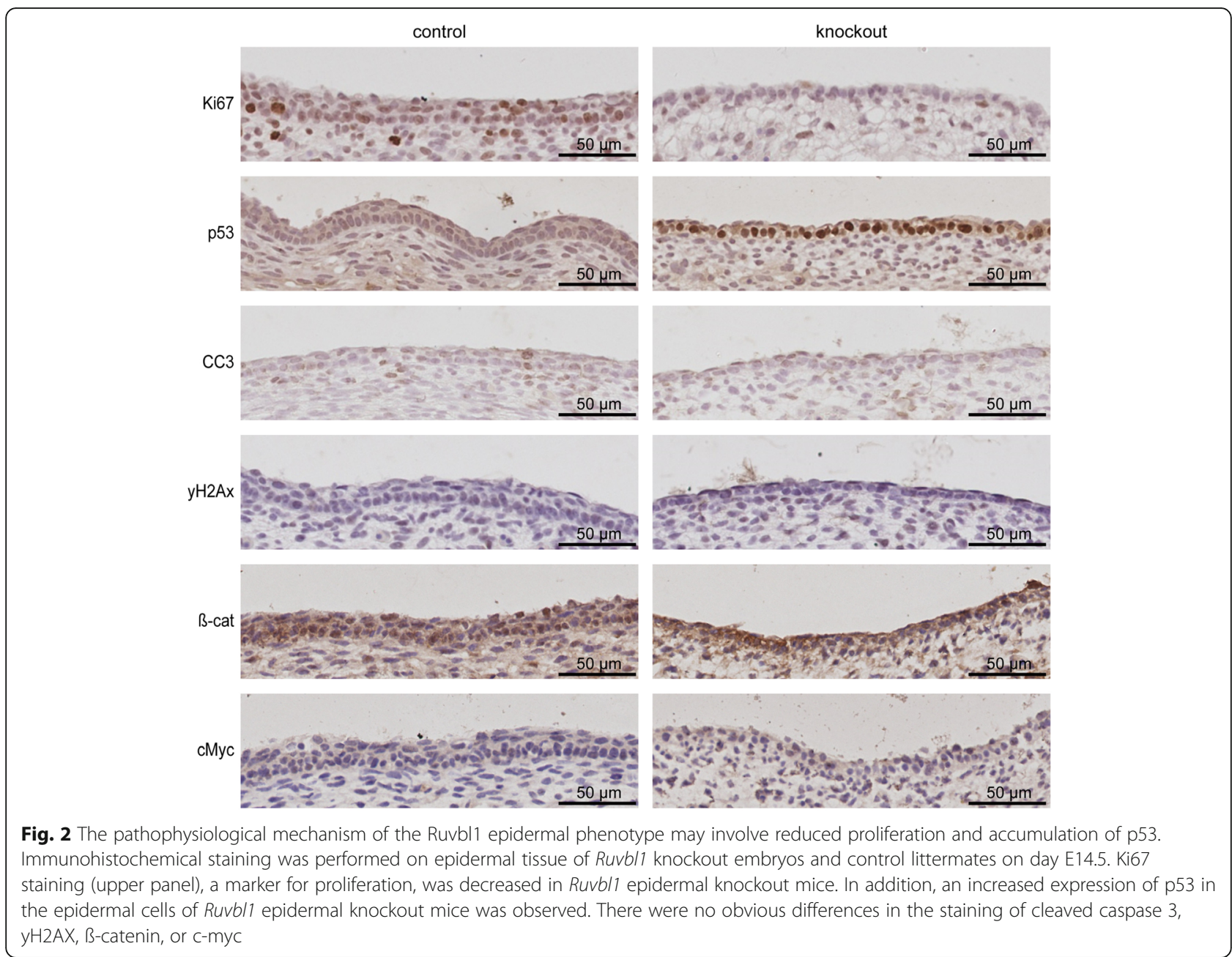

p53 with an activation of subsequent signaling in the epidermis of $\mathrm{Ruvbl}^{\mathrm{f} / \mathrm{fl}} \mathrm{K} 14: \mathrm{Cr} e^{\mathrm{tg}}$ embryos. Interestingly, however, we did not observe clearly altered expression of cleaved caspase 3 or of gammaH2AX, ß-catenin, or c-myc at day E14.5 (Fig. 2).

\section{Discussion}

Mammalian epidermal development is a complex process. To generate the mature epidermis that consists of various layers to protect the body against dehydration or infection, signaling from multiple internal and external sources is integrated $[1,2]$. In this manuscript, we show that the AAA+ superfamily protein Ruvbl1 is crucial for murine epidermal development. Targeted deletion of Ruvbl1 during embryonic development of the epidermis results in severe defects of epidermal function and skin architecture showing that Ruvbl1 is required for the normal development of murine epidermis and skin. Ruvbl1-deficient epidermal cells during development cannot survive and differentiate. Overall skin architecture, e.g., does not show normal development of hair follicles.
The thin layer of cells during early embryonic epidermal development and the nearly complete loss of the K14signal at later stages of development suggest that Ruvbl1 is essential for survival of the epidermal basal cells from which all layers of epidermis are derived and that is required for the development of epidermal appendages.

Given the severity of this very early-onset phenotype, our data remain largely descriptive. Yet the findings can serve as a starting point for future more functional studies. Based on the phenotype and the first initial stainings, it is tempting to speculate that the observed phenotype is likely due to an imbalance of reduced proliferation and increased cell death potentially involving a dysregulation of p53 signaling early in the process. We did not observe evidence for increased detection of cleaved caspase-3 as a marker for apoptosis. However, it is wellknown that p53 can regulate cell proliferation, cell survival, and cell death in response to different types of cellular stress in multiple ways [18]. Additional functional experiments on p53-associated signaling and, e.g., on the expression pattern of epidermal differentiation 
markers or of epigenetic regulators of epidermal development will be required but were beyond the scope of this manuscript with the focus of an initial report of the phenotype. The exact molecular mechanisms underlying the phenotype thus remain to be elucidated.

A link between Ruvbl1 and skin biology and disease has previously been established by the observation of Ruvbl1 and Ruvbl2 autoantibodies in a subcohort of patients suffering from systemic sclerosis but not from other connective tissue diseases $[19,20]$. Patients in which the Ruvbl1/2 autoantibodies were detected showed more myositis and diffuse skin thickening and a high frequency of diffuse cutaneous involvement. These data may point to a role of Ruvbl proteins in the skin even after embryonic development. It may therefore also be interesting to study whether there is a role for Ruvbll in epidermal and skin biology beyond the embryonic phase, thus whether the protein is also essential for the maintenance of epidermal structure and function. Again, more data will be required to shed light into the underlying biology. Given the early embryonically lethal phenotype of the knockout mouse and the severe phenotypes observed in different organs after targeted deletion, it seems unlikely that children with severe variants in RUVBL1 would be born. Children with hypomorphic variants could potentially present with diverse syndromic phenotypes.

In summary, we identify Ruvbl1 as a novel essential player in epidermal development. These observations add novel mammalian in vivo evidence to the growing body of literature on the important role of Ruvbl proteins in cellular proliferation and differentiation.

\section{Supplementary Information}

The online version contains supplementary material available at https://doi. org/10.1186/s40348-021-00111-1.

\section{Additional file 1: Supplemental Figure 1. HE and Ruvbl1}

immunohistochemistry staining of heterozygous mice: Ruvbl1 ${ }^{\mathrm{fl} / \mathrm{wt}} \mathrm{K} 14: \mathrm{Cre}^{\mathrm{tg}}$ mice show remaining expression of Ruvbl1 in immunohistochemistry staining.

\section{Acknowledgements}

The authors thank Martyna Brütting for excellent technical assistance. We also thank Carien Niessen for providing the K14:Cre mouse line and the CECAD imaging facility for technical support.

\section{Authors' contributions}

All indications are according to the CRediT taxonomy: CD: conceptualization, validation, formal analysis, investigation, writing - review and editing, visualization, project administration; TB: resources, writing-review and editing, supervision, funding acquisition; JD: resources, writing-review and editing, supervision, funding acquisition; BS: resources, writing - review and editing, supervision, funding acquisition; MCL: conceptualization, writing —original draft preparation, visualization, supervision, funding acquisition. The authors read and approved the final manuscript.

\section{Funding}

MCL was supported by the German Research Council (DFG; Grant LI 2397 5/ 1) and by the German Federal Ministry of Education and Research (Grant 01GM1903B; Neocyst consortium). Open Access funding enabled and organized by Projekt DEAL.

Availability of data and materials

Original data is available upon reasonable request.

\section{Ethics approval and consent to participate}

All matings and experiments were conducted in accordance with European, national and institutional guidelines, as approved by the State Office of North Rhine-Westphalia, Department of Nature, Environment and Consumer Protection (8.87-50.10.31.08.049 and 84-02.04.2013.A152).

\section{Consent for publication}

Does not apply.

\section{Competing interests}

The authors declare no competing interests.

\section{Author details}

${ }^{1}$ Department of Pediatrics, Faculty of Medicine and University Hospital Cologne, University of Cologne, Kerpener Str. 62, 50937 Cologne, Germany. ${ }^{2}$ Department II of Internal Medicine, Faculty of Medicine and University Hospital Cologne, University of Cologne, Cologne, Germany. ${ }^{3}$ CECAD, Faculty of Medicine and University Hospital Cologne, University of Cologne, Cologne, Germany. ${ }^{4}$ Systems Biology of Ageing Cologne, University of Cologne, Cologne, Germany. ${ }^{5}$ Center for Molecular Medicine, University of Cologne, Cologne, Germany.

Received: 10 November 2020 Accepted: 26 January 2021

Published online: 12 February 2021

\section{References}

1. Hu MS, Borrelli MR, Hong WX, Malhotra S, Cheung ATM, Ransom RC et al (2018) Embryonic skin development and repair. Organogenesis 14(1):46-63

2. Liu S, Zhang H, Duan E (2013) Epidermal development in mammals: key regulators, signals from beneath, and stem cells. Int J Mol Sci 14(6): 10869-10895

3. Abe Y, Tanaka N. Roles of the hedgehog signaling pathway in epidermal and hair follicle development, homeostasis, and cancer. J Dev Biol. 2017; 5(4):12.

4. Koster MI, Roop DR (2007) Mechanisms regulating epithelial stratification. Annu Rev Cell Dev Biol. 23:93-113

5. Nano N, Houry WA (2013) Chaperone-like activity of the AAA+ proteins Rvb1 and Rvb2 in the assembly of various complexes. Philos Trans R Soc Lond B Biol Sci 368(1617):20110399

6. Grigoletto A, Lestienne P, Rosenbaum J (2011) The multifaceted proteins Reptin and Pontin as major players in cancer. Biochim Biophys Acta. 1815(2):147-157

7. Gallant P (2007) Control of transcription by Pontin and Reptin. Trends Cell Biol. 17(4):187-192

8. Jha S, Dutta A (2009) RVB1/RVB2: running rings around molecular biology. Mol Cell 34(5):521-533

9. Boulon S, Bertrand E, Pradet-Balade B (2012) HSP9O and the R2TP cochaperone complex: building multi-protein machineries essential for cell growth and gene expression. RNA Biol. 9(2):148-154

10. Rosenbaum J, Baek SH, Dutta A, Houry WA, Huber O, Hupp TR et al (2013) The emergence of the conserved AAA+ ATPases Pontin and Reptin on the signaling landscape. Sci Signal 6(266):mr1

11. Kakihara Y, Saeki M (2014) The R2TP chaperone complex: its involvement in snoRNP assembly and tumorigenesis. Biomol Concepts. 5(6):513-520

12. Jha S, Shibata E, Dutta A (2008) Human Rvb1/Tip49 is required for the histone acetyltransferase activity of Tip60/NuA4 and for the downregulation of phosphorylation on H2AX after DNA damage. Mol Cell Biol. 28(8):2690-2700

13. Muñoz-Hernández H, Pal M, Rodríguez CF, Prodromou C, Pearl LH, Llorca O (2018) Advances on the structure of the R2TP/Prefoldin-like complex. Adv Exp Med Biol. 1106:73-83 
14. Sykes SM, Mellert HS, Holbert MA, Li K, Marmorstein R, Lane WS et al (2006) Acetylation of the p53 DNA-binding domain regulates apoptosis induction. Mol Cell 24(6):841-851

15. Dafinger $C$, Rinschen MM, Borgal L, Ehrenberg C, Basten SG, Franke M et al (2018) Targeted deletion of the AAA-ATPase Ruvbl1 in mice disrupts ciliary integrity and causes renal disease and hydrocephalus. Exp Mol Med 50(6):75

16. Bereshchenko O, Mancini E, Luciani L, Gambardella A, Riccardi C, Nerlov C (2012) Pontin is essential for murine hematopoietic stem cell survival. Haematologica. 97(9):1291-1294

17. Indra AK, Li M, Brocard J, Warot X, Bornert JM, Gérard C et al (2000) Targeted somatic mutagenesis in mouse epidermis. Horm Res. 54(5-6):296-300

18. Kruiswijk F, Labuschagne CF, Vousden KH (2015) p53 in survival, death and metabolic health: a lifeguard with a licence to kill. Nat Rev Mol Cell Biol. 16(7):393-405

19. Kaji K, Fertig N, Medsger TA, Satoh T, Hoshino K, Hamaguchi Y et al (2014) Autoantibodies to RuvBL1 and RuvBL2: a novel systemic sclerosis-related antibody associated with diffuse cutaneous and skeletal muscle involvement. Arthritis Care Res. 66(4):575-584

20. Nomura Y, Ueda-Hayakawa I, Yamazaki F, Ozaki Y, Hamaguchi Y, Takehara K et al (2020) A case of anti-RuvBL1/2 antibody-positive systemic sclerosis overlapping with myositis. Eur J Dermatol 30(1):52-53

\section{Publisher's Note}

Springer Nature remains neutral with regard to jurisdictional claims in published maps and institutional affiliations.

\section{Submit your manuscript to a SpringerOpen ${ }^{\circ}$ journal and benefit from:}

- Convenient online submission

- Rigorous peer review

- Open access: articles freely available online

- High visibility within the field

- Retaining the copyright to your article

Submit your next manuscript at $\boldsymbol{\nabla}$ springeropen.com 